\title{
Depleting hypothalamic somatostatinergic neurons recapitulates diabetic phenotypes in mouse brain, bone marrow, adipose and retina
}

\author{
Chao Huang ${ }^{1}$ (D) - Robert F. Rosencrans ${ }^{1}$ (D) Raluca Bugescu ${ }^{2} \cdot$ Cristiano P. Vieira $^{1}$ (D) $\cdot$ Ping Hu $^{1}$. \\ Yvonne Adu-Agyeiwaah ${ }^{1}$ (D) Karen L. Gamble $^{3}$ (D) Ana Leda F. Longhini ${ }^{1} \cdot$ Patrick M. Fuller $^{4}$ (D) \\ Gina M. Leinninger ${ }^{2}$ (D) $\cdot$ Maria B. Grant ${ }^{1}$ (D)
}

Received: 1 April 2021 / Accepted: 11 June 2021 / Published online: 24 August 2021

(C) The Author(s), under exclusive licence to Springer-Verlag GmbH Germany, part of Springer Nature 2021

\begin{abstract}
Aims/hypothesis Hypothalamic inflammation and sympathetic nervous system hyperactivity are hallmark features of the metabolic syndrome and type 2 diabetes. Hypothalamic inflammation may aggravate metabolic and immunological pathologies due to extensive sympathetic activation of peripheral tissues. Loss of somatostatinergic (SST) neurons may contribute to enhanced hypothalamic inflammation.

Methods The present data show that leptin receptor-deficient $(d b / d b)$ mice exhibit reduced hypothalamic SST neurons, particularly in the periventricular nucleus. We model this finding, using adeno-associated virus delivery of diphtheria toxin subunit A (DTA) driven by an SST-cre system to deplete these neurons in $S s t^{\text {cre/gfp }}$ mice (SST-DTA).

Results SST-DTA mice exhibit enhanced hypothalamic c-Fos expression and brain inflammation as demonstrated by microglial and astrocytic activation. Bone marrow from SST-DTA mice undergoes skewed haematopoiesis, generating excess granulocytemonocyte progenitors and increased proinflammatory (C-C chemokine receptor type 2; CCR2 ${ }^{\text {hi }}$ ) monocytes. SST-DTA mice exhibited a 'diabetic retinopathy-like' phenotype: reduced visual function by optokinetic response $(0.4$ vs 0.25 cycles/degree; SST-DTA vs control mice); delayed electroretinogram oscillatory potentials; and increased percentages of retinal monocytes. Finally, mesenteric visceral adipose tissue from SST-DTA mice was resistant to catecholamine-induced lipolysis, displaying $50 \%$ reduction in isoprenaline (isoproterenol)-induced lipolysis compared with control littermates. Importantly, hyperglycaemia was not observed in SST-DTA mice.

Conclusions/interpretation The isolated reduction in hypothalamic SST neurons was able to recapitulate several hallmark features of type 2 diabetes in disease-relevant tissues.
\end{abstract}

Keywords Diabetes $\cdot$ Electroretinogram $\cdot$ Hypothalamus $\cdot$ Monocytosis $\cdot$ Neuroimmunology $\cdot$ Retina $\cdot$ Somatostatin

Chao Huang and Robert Follett Rosencrans contributed equally to this work.

Maria B. Grant

mariagrant@uabmc.edu

1 Department of Ophthalmology, University of Alabama at Birmingham, Birmingham, AL, USA

2 Department of Physiology, Michigan State University, East Lansing, MI, USA

3 Department of Psychiatry and Neurobehavioral Neurobiology, University of Alabama at Birmingham, Birmingham, AL, USA

4 Department of Neurology, Beth Israel Deaconess Medical Center and Division of Sleep Medicine, Harvard Medical School, Boston, MA, USA

$\begin{array}{ll}\text { Abbreviations } \\ \text { AAV } & \text { Adeno-associated virus } \\ \text { ACK } & \text { Ammonium chloride potassium } \\ \text { CNS } & \text { Central nervous system } \\ \text { CCR2 } & \text { C-C chemokine receptor type 2 } \\ \text { DIO } & \text { Double-floxed inverse orientation } \\ \text { DTA } & \text { Diphtheria toxin subunit A } \\ \text { ERG } & \text { Electroretinogram } \\ \text { GFAP } & \text { Glial fibrillary acidic protein } \\ \text { GFP } & \text { Green fluorescent protein } \\ \text { GMP } & \text { Granulocyte-monocyte progenitor } \\ \text { HFD } & \text { High-fat diet } \\ \text { Iba-1 } & \text { Ionised calcium binding adaptor molecule 1 }\end{array}$




\section{Research in context}

\section{What is already known about this subject?}

- Somatostatinergic (SST) neuronal loss and inflammation are observed in the hypothalamus of type 2 diabetes models

- Somatostatin regulates both inflammatory cytokine secretion and sympathetic nerve activity in the hypothalamus

- Hypothalamic inflammation and bone marrow sympathetic neuropathy precede diabetic retinopathy by driving a proinflammatory immune system myeloid bias

\section{What is the key question?}

- Is SST neuronal loss sufficient to induce hypothalamic inflammation and mimic diabetic phenotypes in bone marrow, adipose tissue and retina?

\section{What are the new findings?}

- SST neuronal loss is sufficient for hypothalamic inflammation, bone marrow myeloid bias, classical blood monocyte phenotype and retinal dysfunction

- Visceral mesenteric adipose tissue is also impacted by SST neuronal loss

\section{How might this impact on clinical practice in the foreseeable future?}

- $\quad$ Future studies will show whether the effect of SST neuronal loss can be ameliorated by pharmacological treatment using the somatostatin analogue, octreotide, which is FDA approved and can target the hypothalamus via the intranasal route

\section{iWAT Inguinal fat}

mWAT Mesenteric fat

OP Oscillatory potential

PVN Paraventricular nucleus

SNS Sympathetic nervous system

SST Somatostatinergic

\section{Introduction}

Hypothalamic inflammation and sympathetic nervous system (SNS) hyperactivity are important upstream causes of metabolic and immunological pathologies in type 2 diabetes and the metabolic syndrome. Both genetic and dietary models of these diseases elicit hypothalamic inflammation and elevations in sympathetic outflow, often early in the disease course [1-3]. Emerging evidence shows that inflammation also sensitises the hypothalamus to ascending sensory innervation, enhancing sympathetic outflow [4]. Thus, inflammation, sympathetic nerve hyperactivity and metabolic disease are redundantly linked. In keeping with the theory that hypothalamic dysregulation is a primary event driving the metabolic syndrome, exogenous induction of hypothalamic inflammation recapitulates many features of the metabolic syndrome, whereas central nervous system (CNS)-penetrating anti- inflammatory agents ameliorate many features of the metabolic syndrome $[5,6]$. Centrally acting sympatholytic agents comparably improve hypertension, hyperlipidaemia and insulin resistance [7]. Strikingly, many studies have induced central inflammation using dietary, genetic or pharmacological approaches. However, comparatively few studies have modulated endogenous protective mechanisms, especially those which are damaged by the underlying disease process.

In this regard, the somatostatinergic (SST) system is a particularly attractive therapeutic target because it both negatively regulates sympathetic outflow [8-12] and frequently inhibits inflammatory cytokine secretion [13, 14]. Exogenous somatostatin preserves the brain endothelial tight junctions against lipopolysaccharide challenge [15], inhibits prostaglandin $E_{2}$ synthesis in microglia [16] and reduces IL-6 secretion from astrocytes [17]. However, conflicting studies exist [18, 19], and most current data relies on in vitro models, highlighting the need for further study. Most critically, hypothalamic SST neurons are depleted in preclinical models of the metabolic syndrome and type 2 diabetes [20], suggesting that dysfunction in an endogenous anti-inflammatory, sympatholytic neuronal population could contribute to hypothalamic inflammation and SNS hyperactivity.

Because the hypothalamus is a master regulator of homeostasis, hypothalamic inflammation may induce profound dysfunction across many organ systems. Perhaps nowhere is 
this more concerning than in the immune system, because impaired neuroimmune regulation could initiate positive feedback loops sustaining hypothalamic inflammation. Specifically, altered sympathetic outflow to lymphoid organs may increase granulocyte-monocyte progenitor (GMP) production, driving the myeloidosis observed in diabetic individuals and animal models $[21,22]$. These immune cells may in turn infiltrate the hypothalamus, further dysregulating autonomic outflow, as has recently been shown in neurogenic hypertension [23]. Thus, hypothalamic dysfunction has the capacity to induce downstream injury directly through hyperactivation of sympathetic nerves, as well as indirectly through the altering of immune homeostasis and initiation of systemic inflammation. For example, bone marrow neuropathy induced increases in proinflammatory monocytes precedes diabetic retinopathy in preclinical models $[20,24]$.

Other disruptions in neural regulation may result from direct nerve hyperactivity. For example, noradrenaline (norepinephrine) turnover (NETO) in adipose tissue is rapidly increased under dietary challenge $[25,26]$. Additionally, adipose tissue exhibits a blunted lipolytic response to sympathetic nerve input in humans and in animal models [27-30] but little data explore whether this dysfunction is caused by the aforementioned increase in sympathetic nerve activity.

The primary objective of this study was to test the hypothesis that SST neuronal ablation is sufficient to induce hypothalamic inflammation, hypothalamic neuronal hyperactivity, bone marrow myeloidosis, proinflammatory blood monocytes and retinal dysfunction. A secondary endpoint of the study was to examine additional metabolic effects of SST neuronal ablation, particularly in visceral adipose tissue.

\section{Methods}

\section{Mice}

All protocols were approved by the University of Alabama at Birmingham (UAB) IACUC. SST reporter mice (SST ${ }^{\text {cre/gfp }}$ ) were bred on a C57B16 background by Jax Laboratories (USA) in their animal facility by crossing $S s t^{\text {tm2.1(cre)Zjh }}$ (Jax Strain 013044) to the cre-dependent reporter line B6.Cg-

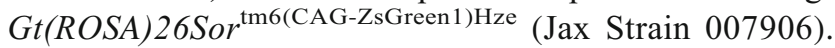
Mice that were heterozygous at both genomic insertions were used, with 24 mice per group, equal numbers of males and females. Injections (100-200 $\mathrm{nl}$ per side) were performed by a trained operator at UAB. All mice were given presurgical buprenorphine and anaesthetised with isoflurane. The following stereotactic coordinates were used in mice aged 8-10 weeks: anteroposterior -0.5 ; mediolateral \pm 0.220 ; dorsoventral -4.8 ). The control adeno-associated virus (AAV) was a double-floxed inverse orientation (DIO) vector, hSyn-DIO-GFP-AAV (SSTGFP). Cre-dependent expression of the diphtheria toxin subunit
A (DTA) was achieved via AAV delivery of the DIO vector hSyn-DIO-DTA-mCherry-AAV, provided by P. M. Fuller [31, 32]; SST-DTA $d b / d b$ mice were purchased from Jax Laboratories along with heterozygous $d b / m$ littermates (Jax Strain 000697). Mice were group-housed in specific-pathogenfree environments and fed chow diet ad libitum under a $12 \mathrm{~h}$ light-dark cycle at $22^{\circ} \mathrm{C}$. Experimenters were masked to treatment conditions. Male and female mice were used in all studies.

\section{Immunohistochemistry}

Brains were fixed in $4 \%$ paraformaldehyde, cryoprotected in $30 \%$ sucrose and embedded in optimal cutting temperature media, followed by sectioning at $14 \mu \mathrm{m}$ thickness and storage at $-20^{\circ} \mathrm{C}$. Brain sections were washed twice in PBS for $10 \mathrm{~min}$ and blocked in $1 \% \mathrm{BSA}$ in $0.3 \%$ Triton- $\mathrm{X}$ for $30 \mathrm{~min}$ at room temperature. The following primary antibodies were incubated overnight: rat anti-somatostatin (Abcam, USA; M09204; 1:100), rabbit anti-NeuN (Thermo Fisher Scientific, USA; PA5-78499; 1:100), rabbit anti-c-Fos (Abcam; ab90289; 1:100), rabbit anti-ionised calcium binding adaptor molecule 1 (Iba-1; Wako, Osaka, Japan; 019-19741; 1:200) and rabbit anti-glial fibrillary acidic protein (GFAP) (Abcam; ab33922; 1:100). Sections were then transferred to species-specific secondary antibodies conjugated with either AlexaFluor 594 (1:200) or AlexaFluor 488 (1:100), both from InvitrogenMolecular Probes (Carlsbad, CA, USA) for $1.5 \mathrm{~h}$ at room temperature. Following two additional PBS washes, sections were reacted with DAPI (Invitrogen by Thermo Fisher Scientific; D3571; 1:10,000) for 10 min and mounted in antifade mounting medium (Vector Labs, USA). Somatostatin visualisation required antigen retrieval in citrate buffer (Sigma Aldrich; C8532; pH 6.0) for 30 min prior to blocking. Liver Nile Red (Thermo Fisher Scientific; N1142; $12 \mu \mathrm{g} / \mathrm{ml}$ ) staining was performed for $2 \mathrm{~h}$ at room temperature. All sections were examined using fluorescence microscopy with a Zeiss Axio Imager Z2 (Carl Zeiss Microscopy; USA). Cell counting was performed in ImageJ (Version 1.8.0; National Institutes of Health, USA).

\section{Adipose tissue lipolysis}

Pieces of mesenteric and subcutaneous inguinal fat pads (50 $100 \mathrm{mg}$ ) were incubated in basal lipolysis media (low-glucose DMEM with $4 \%$ fatty-acid-free BSA) at $37^{\circ} \mathrm{C}$ with $4 \% \mathrm{CO}_{2}$ for 1-3 $\mathrm{h}$, then transferred to induced lipolysis media (lowglucose DMEM with $4 \%$ fatty-acid-free BSA, $10 \mu \mathrm{mol} / 1$ Triacsin $\mathrm{C}$ to inhibit fatty acid re-esterification and $10 \mu \mathrm{mol} /$ 1 isoprenaline [isoproterenol]) for $1 \mathrm{~h}$. Following lipolysis, media was stored at $4{ }^{\circ} \mathrm{C}$ until assayed for free glycerol (Sigma Free Glycerol Kit; MAK 117) with detection using a Biotek Epoch microplate spectrophotometer at $550 \mathrm{~nm}$. Lipolysis was calculated as the ratio of free glycerol in 
induced media to the free glycerol in basal media, normalised for duration of basal lipolysis [28].

\section{Fatty acid and triacylglycerol measurements}

Plasma NEFA was measured using Wako Diagnostics NonEsterified Free fatty acid kit (Wako, Japan; 999-34691). Triacylglycerols were measured using the T2449 Triglyceride Kit (Sigma Aldrich, USA).

\section{Flow cytometry}

Peripheral blood flow cytometry Blood was collected under isoflurane anaesthesia via cheek bleed into heparinised capillary tubes. Blood was centrifuged at $400 \mathrm{~g}$ at $4^{\circ} \mathrm{C}$ for $7 \mathrm{~min}$, plasma was collected, packed cells were resuspended in cold ammonium chloride potassium (ACK) lysis buffer and lysed for $15 \mathrm{~min}$ on ice, then centrifuged at $400 \mathrm{~g}$ at $4^{\circ} \mathrm{C}$ for $5 \mathrm{~min}$. Cells were washed twice in $5 \mathrm{ml}$ of sterile, filtered BEP ( $2 \%$ fatty-acid-free BSA, $1 \%$ EDTA, in PBS), and centrifuged at $400 \mathrm{~g}$ for $5 \mathrm{~min}$. Following washes, cells were stained (see Electronic supplementary material [ESM] Table 1 for flow cytometry panels) for $20 \mathrm{~min}$ at room temperature in the dark, then washed twice. Flow cytometry was performed using a BD Celesta and BD FACSymphony. Analysis was performed using FlowJo version 10.7.1 (FlowJo, USA). All antibodies are listed in ESM Table 1. Gating schema are shown in ESM Figs 1 and 2.

Bone marrow flow cytometry Whole femurs were cleared of musculature using sterile gauze. The distal and proximal epiphysis were resected and bone marrow was flushed using $6 \mathrm{ml}$ of sterile FEB buffer (Fisher Scientific, USA; 10-082$147 ; 2 \%$ fetal bovine serum and $1 \mathrm{mmol} / \mathrm{l}$ EDTA in PBS). The single-cell suspension was stored on ice until centrifuged. Erythrocyte lysis was achieved with ACK lysis buffer for $15 \mathrm{~min}$ on ice and arrested with $10 \mathrm{ml} \mathrm{FEB}$ buffer before centrifugation, washing and staining; flow cytometry was performed as outlined above.

Retina flow cytometry Retina was isolated and stored on ice until digestion with $1 \mathrm{ml}$ RPMI containing 5\% FBS supplemented with collagenase D and DNase at $37^{\circ} \mathrm{C}$ for $1 \mathrm{~h}$ with periodic vortexing. The resulting suspension was filtered through a $70 \mu \mathrm{m}$ cell strainer with sterile FEB buffer and centrifuged. Cell pellets were resuspended into $200 \mu \mathrm{l}$ of FEB, and stained; flow cytometry was performed as outlined above.

\section{Electroretinogram}

Electroretinograms (ERGs) were recorded using the LKC Bigshot ERG apparatus. Mice were dark-adapted overnight, anaesthetised with ketamine and xylazine in sterile $0.9 \%$ saline ( $80 \mathrm{mg} / \mathrm{kg}$ and $15 \mathrm{mg} / \mathrm{kg}$, respectively), and then pupils were dilated with eye drops of phenylephrine $(2.5 \%$; Paragon BioTeck, USA). Contact lens electrodes were placed with Gonak (hypromellose 2.5\%; Akorn, USA), as well as a steel reference electrode (head), and a steel ground electrode (foot). Mice were exposed to five full-field white light flashes at 0.25 and $2.5 \mathrm{~cd} . \mathrm{s} / \mathrm{m}^{2}$ (scotopic), light-adapted for $5 \mathrm{~min}$ and exposed to $10-15$ full-field white light flashes at 10 and $25 \mathrm{~cd} . \mathrm{s} / \mathrm{m}^{2}$ (photopic).

\section{Optokinetic tracking responses}

A trained observer-operator, masked to treatment condition, assessed visual acuity by observing reflexive head tracking movements (optomotor response) using a virtual optomotor system (OptoMotry; Cerebral Mechanics, Canada) with custom software (OptoMotry HD software version 2.0.0[4907]). The mice were placed on a platform inside a four-walled chamber made of computer monitors displaying gratings ranging from 0.2 to 0.5 cycles per degrees rotating at 12.0 degrees/s shown under photopic conditions at $100 \%$ contrast. Visual acuity was defined as the highest grating frequency at which optomotor response could be reliably detected.

\section{Noradrenaline content and plasma hormones}

Whole fat pads were homogenised in ice-cold perchloric acid $(0.4 \mathrm{~mol} / \mathrm{l})$ with reduced glutathione $(5 \mathrm{mmol} / \mathrm{l})$. Noradrenaline was measured by HPLC-electrochemistry at the Vanderbilt Hormone Assay Core. The supernatant fraction was extracted with $10 \mathrm{mg}$ of acid-washed alumina, eluted, preconcentrated, and injected via an ESA model 542 autosampler (ESA Biosciences, USA) onto an ESA HR-80, reverse phase, 3 micron column and an ESA model 5200A Coulochem II electrochemical detector. Results were analysed using EZ Chrom software 3.2.0 (Agilent, USA). Adiponectin was measured via ELISA (MRP300; R\&D Systems, USA), as was insulin (Alpco, USA; 80-INSMR-CH10).

\section{Quantitative PCR}

Adipose samples ( $40 \mathrm{mg}$ ) were rapidly dissected and snap frozen in DNAse/RNAse free tubes over liquid nitrogen and stored at $-80^{\circ} \mathrm{C}$ until homogenisation with Qiagen TissueLyser LT in Trizol. RNA was purified (DirectZol RNA Miniprep; ZymoResearch, USA; R2051) with on-column DNAse treatment followed by reverse transcription (Superscript IV VILO; Thermofisher; 11756050). cDNA (1 $\mu$ l of a 1:10 dilution) was used in a $10 \mu \mathrm{l}$ reaction volume as follows: $\beta 3$-AR transcripts were amplified (forward primer TGACTCCTGAAACA AGCGGG, reverse primer GTGGGAATTGGAGGGTGGAG) and compared with cyclophilin A (forward primer CAGACGCC 
ACTGTCGCTTT, reverse primer TGTCTTTGGAACTT TGTCTGCAA) via SYBR Green (Biorad, USA; 1725271). Specificity was measured via melting curve and confirmed via amplicon size in agarose gel electrophoresis.

\section{Statistical analyses, data and resource availability}

All statistical analyses were conducted using GraphPad Prism 8.2.0 (GraphPad, USA). Two-sample $t$ tests were used to detect significant differences $(p<0.05)$ between SST-DTA and SSTGFP groups. Welch's $t$ tests were used if variance between groups was unequal. Data are presented as means \pm SD unless otherwise noted. Data in dot plots represent individual replicates. The only criterion for the exclusion of data was early death or a wound (e.g. ulcerative dermatitis). No difference in event rates was observed between groups. One sample (of ten) from the control group was discarded from the insulin analysis on the basis of a Grubb's extreme Studentised deviate analysis at $p<0.05$.

\section{Results}

\section{Aged $d b / d b$ hypothalamus exhibits a loss of SST neurons}

Previous data indicated a reduction in hypothalamic SST neurons in BBZ/WoR rat hypothalamus [20]. We tested the hypothesis that this phenomenon was a general finding in models of the metabolic syndrome and type 2 diabetes by examining SST neuron density in the leptin-receptor-deficient $d b / d b$ mouse model of the metabolic syndrome and type 2 diabetes. Serial coronal sections of the paraventricular nucleus (PVN) and periventricular nucleus were examined using immunohistochemistry for somatostatin (Fig. 1a). Sections were oriented with reference to the Allen Brain Atlas. SST neuron density varied systematically between the PVN and periventricular nucleus, with an overall higher abundance of SST neurons in the periventricular nucleus (Fig. 1b,c). A strong rostral-caudal gradient was observed in the periventricular nucleus, with the highest densities of SST neurons between Bregma coordinates -0.3 to -1.1 in hypothalamus from $\mathrm{db} / \mathrm{m}$ control mice. A significant reduction in the abundance of SST neurons was observed at most Bregma levels in the periventricular nuclei of $d b / d b$ mice compared with $d b / \mathrm{m}$ control mice (Fig. 1b), whereas PVN SST neuron density exhibited reductions at only one Bregma level (Fig. 1c).

\section{AAV-DTA treatment depletes SST cells and induces hypothalamic inflammation}

To mimic the observed reduction in the abundance of SST neurons, $S s t^{\text {cre/gfp }}$ mice received stereotactic injections of AAV containing a cre-driven $\alpha$ subunit of diphtheria toxin into the hypothalamus (SST-DTA), which is sufficient to induce neural cell death [31, 32]. Control mice received a virus containing a green fluorescent protein (GFP) construct (SST-GFP). At 1 week post-treatment, a robust reduction in the abundance of SST neurons was observed in the hypothalamus of SST-DTA mice
Fig. 1 Reduced somatostatin immunofluorescence in $d b / d b$ mouse paraventricular and periventricular hypothalamus. (a) Coronal sections of hypothalamus from $d b / d b$ mice at 12 months of age exhibited a reduction in immunofluorescent somatostatin staining, compared with heterozygote littermate control $(d b / \mathrm{m})$ mice. $(\mathbf{b}, \mathbf{c})$ Cell counts of somatostatin-positive nuclei in the periventricular nucleus (b) and paraventricular nucleus (c) from Bregma 0.0 to Bregma -1.6 . $n=5 \mathrm{db} / \mathrm{db}, n=6 \mathrm{db} / \mathrm{m} * p<0.05$ for indicated comparison a
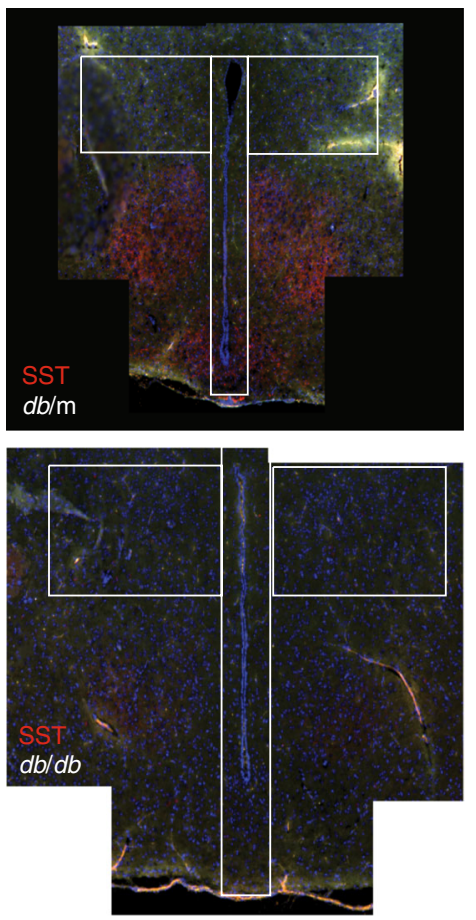

b

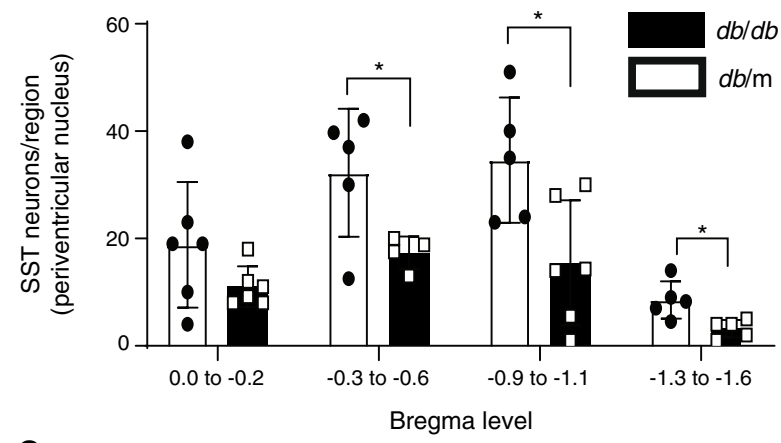

C

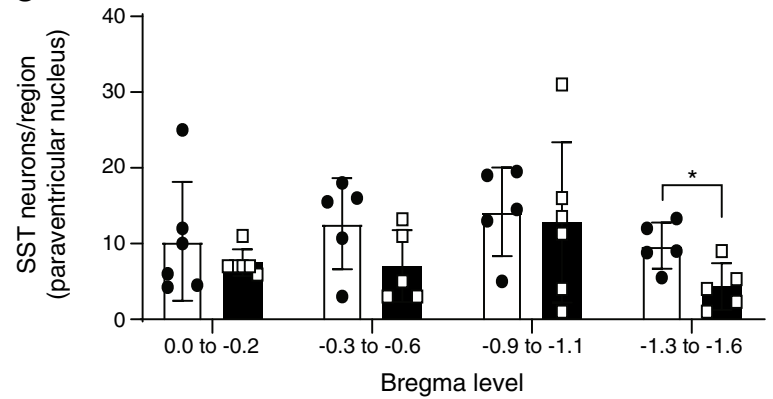




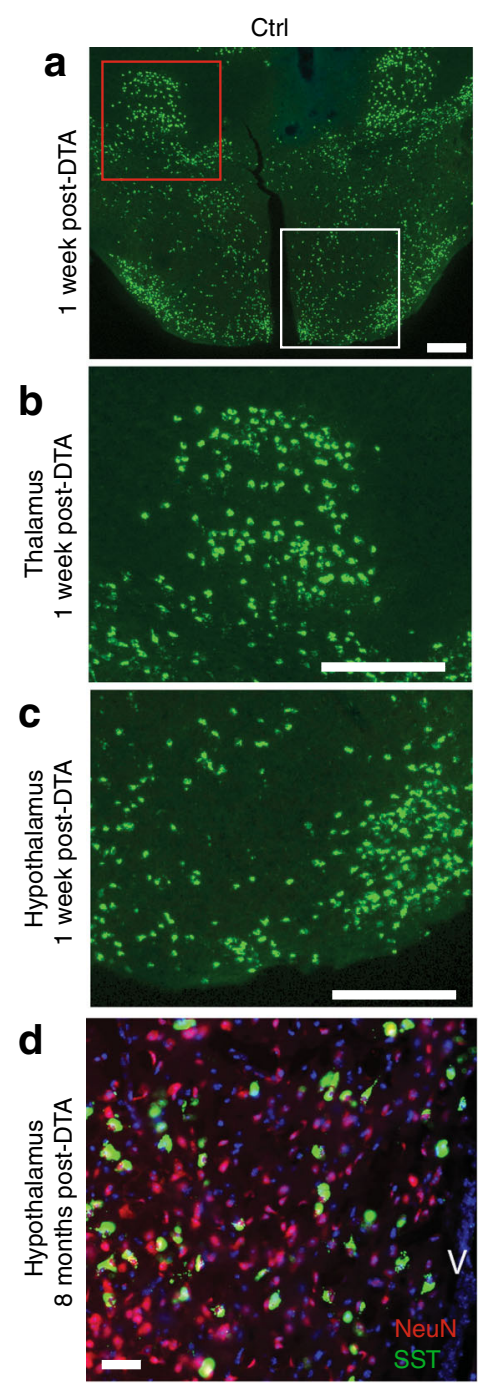

Fig. 2 AAV-DTA delivery reduces the abundance of hypothalamic SST neurons in mice. (a) At 1 week post-injection, a large reduction in the abundance of SST-GFP ${ }^{+}$neurons was observed in the hypothalamus (white box) but not the adjacent brain regions (such as the ventromedial thalamus; red box) of SST-DTA mice. Scale bar, $100 \mu \mathrm{m}$. (b, c) Higher magnification images indicate comparable abundance of SST neurons (SST-DTA vs SST-GFP control mice) in the thalamus (b) but not the hypothalamus (c). Scale bar, $100 \mu \mathrm{m}$. (d) At 8 months post-DTA, SSTDTA mice exhibited sustained loss of SST neurons, with small changes in
SST-DTA
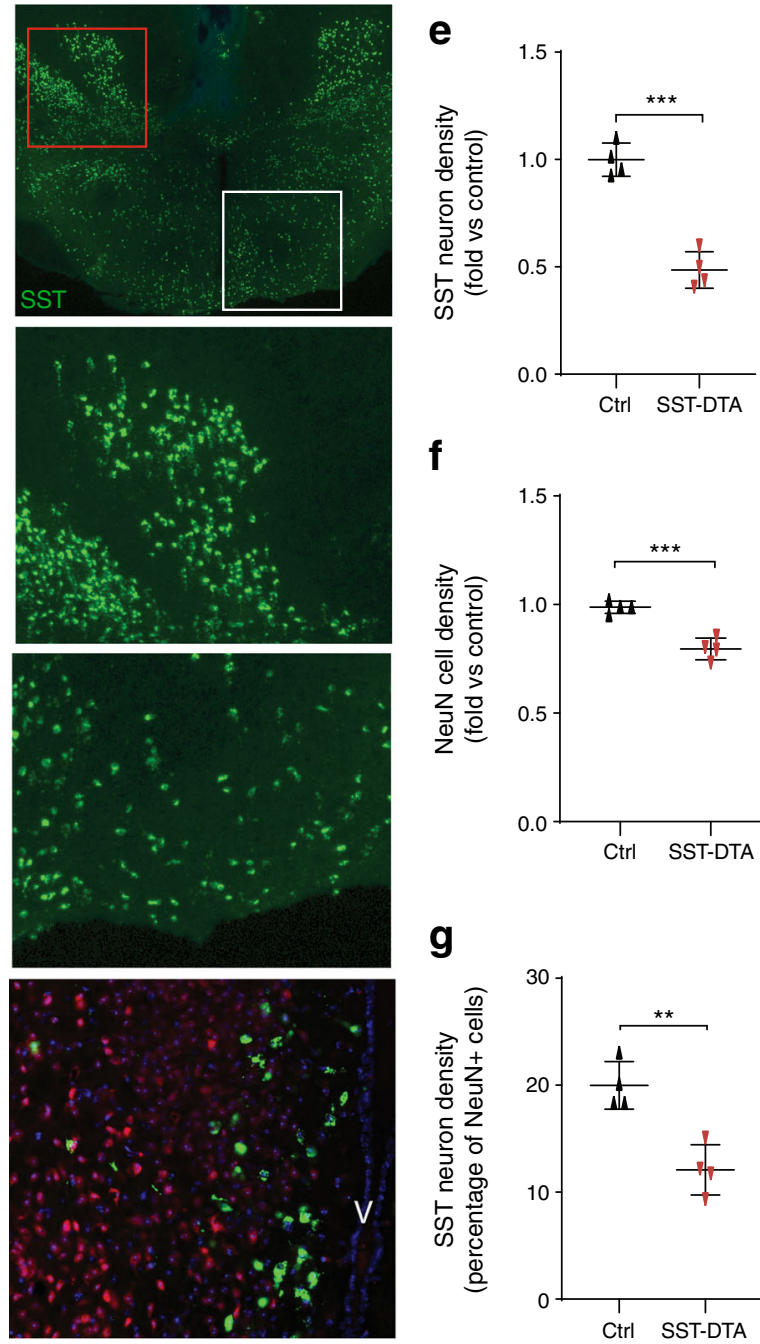

f

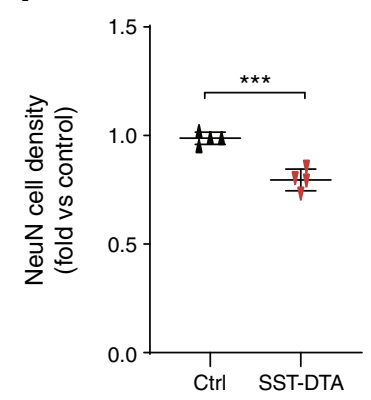

\section{g}

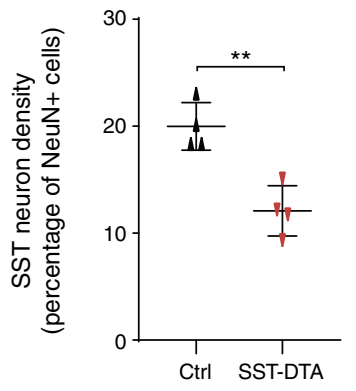

but not in neighbouring brain regions such as the ventromedial thalamus (Fig. 2a-c). At 8 months post-DTA exposure, SST neuronal density remained suppressed (Fig. 2d,e). A smaller reduction in the overall abundance of NeuN-positive cells was observed (Fig. 2f), indicating that SST neurons were preferentially eliminated by this approach. This finding is strengthened by the observation that relativising SST density to overall NeuN density still demonstrated a significant loss in SST-DTA mice (Fig. 2g).

Concomitant with these findings, at 8 months, SSTDTA mice exhibited increased abundance of Iba- $1^{+}$ microglia (Fig. 3a) and GFAP $^{+}$astrocytes (Fig. 3b).
NeuN-positive neurons in red. Scale bar, $50 \mu \mathrm{m}$. (e) Quantification of the reduction in SST neurons in DTA-treated mice compared with AAVGFP mice; cell densities were calculated per field and relativised to control mice. (f, g) Quantification of reduction in NeuN in SST-DTA mice showed the loss was significant (f); however, relativising SST density to NeuN density indicated significant SST loss (g). $n=4$ SST-DTA, $n=4$ control. $* * p<0.01$ and $* * * p<0.001$ for indicated comparison. Ctrl, control; $\mathrm{V}$, third ventricle of the brain

These data suggest that depleting hypothalamic SST neurons is sufficient to induce hypothalamic neuroinflammation, which persists long after the initial DTA-mediated cell death. SST neurons often act as local inhibitors of neural activity [8]; as such, their ablation should induce neural hyperactivity and increase sympathetic outflow. To test this hypothesis, immunohistochemistry for c-Fos positivity in hypothalamic sections (a commonly utilised proxy for recent cell activation [33]) was undertaken. Hypothalamuses of SST-DTA mice displayed significantly higher densities of c-Fos ${ }^{+}$cells than those of control mice (Fig. 3c). 
Fig. 3 SST-DTA mice exhibit hypothalamic inflammation and hyperactivity. (a-c)

Representative

immunofluorescent images of Iba- $1^{+}$cells (red, a), GFAP ${ }^{+}$cells (red, b) and c-Fos ${ }^{+}$cells (red, c), labelled for somatostatin (green, GFP) and nuclei (blue, DAPI). Graphs show cell densities calculated per microscopic field and relativised to control mice. $n=4$ SST-DTA, $n=4 * p<0.05$ and $* * p<0.01$ for indicated comparison. Arrowheads indicate c-Fos ${ }^{+}$cells. Scale bars, $50 \mu \mathrm{m}$. Ctrl, control; $\mathrm{V}$, third ventricle of the brain a
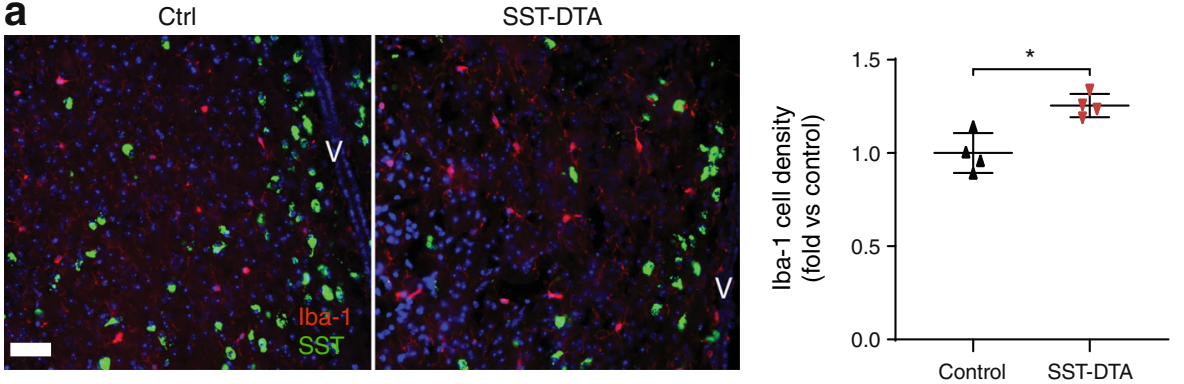

b
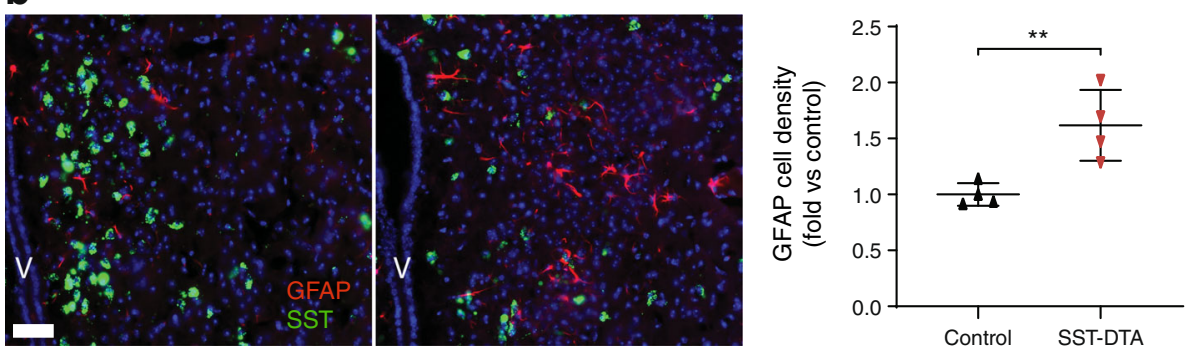

c
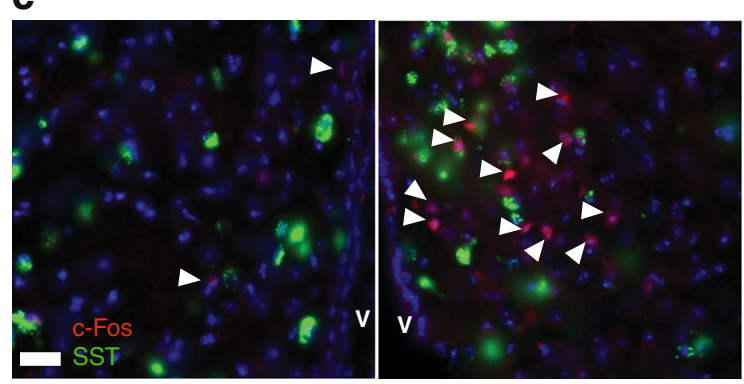

a

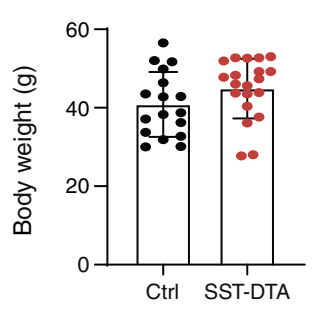

e

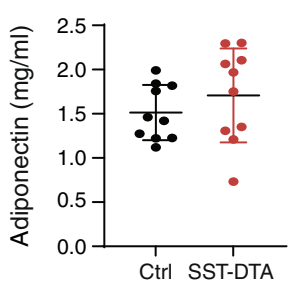

b

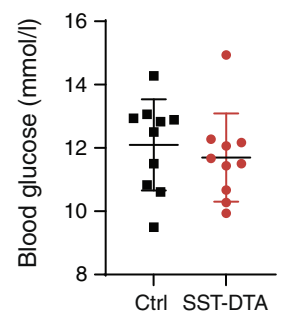

f

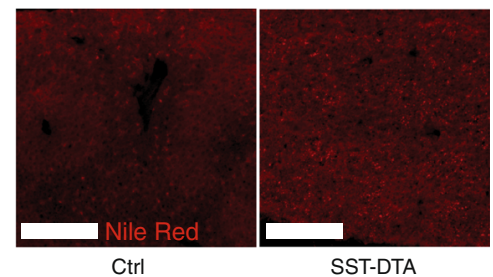

C

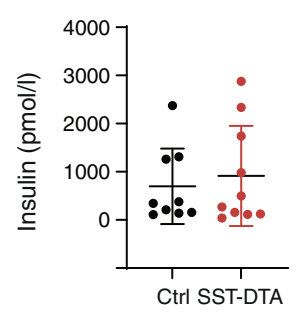

d

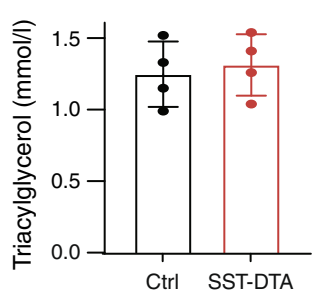

g

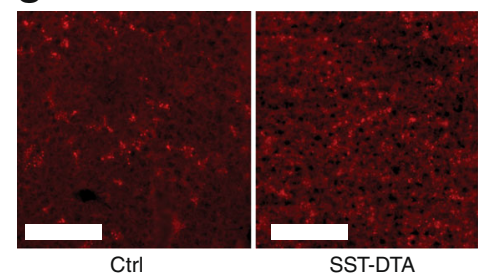

Fig. 4 SST-DTA mice do not exhibit hyperglycaemia, hyperinsulinaemia or hyperlipidaemia. (a-d) Body weight measurements at 8 months of age showed no overall trend (a) ( $n=20 /$ group), nor did blood glucose measurements (b) or insulin (c) ( $n=10 /$ group), or triacylglycerol (d; $n=4 /$ group). (e) Plasma adiponectin was not depleted in DTA mice
( $n=10 /$ group). (f, g) Nile Red neutral lipid staining of livers from SSTDTA and control mice did not show gross lipid deposits at $10 \times$ magnification (f; scale bar, $50 \mu \mathrm{m})$; higher resolution images (g; 20×; scale bar, $25 \mu \mathrm{m})$ showed small lipid droplets within a normal range. Ctrl, control 

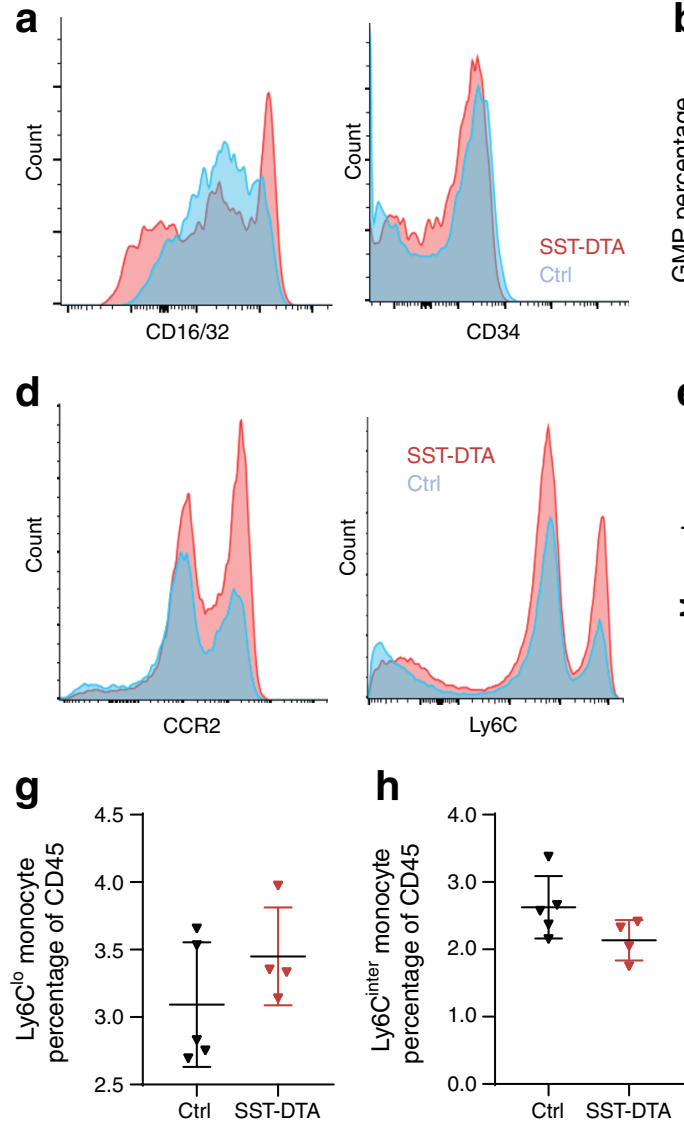

Fig. 5 SST-DTA mice exhibit altered haematopoiesis and circulating monocytes. (a) Histograms showing counts of SST-DTA (red) and control (blue) $\mathrm{CD} 16^{+}, \mathrm{CD} 32^{+}$and $\mathrm{CD} 34^{+}$cells. (b, c) SST-DTA mice show increases in bone marrow GMPs (b), with concomitant decreases in bone marrow megakaryocyte-erythroid progenitors (MEPs) (c). (d) Histograms for monocytes expressing CCR2 and Ly6C. (e, f) DTA-treated mice exhibited a relative monocytosis (e) and an increase in classical

\section{SST-DTA mice do not exhibit hyperglycaemia, hyperinsulinaemia or hyperlipidaemia}

No difference in weight was observed in SST-DTA vs control mice (Fig. 4a), nor were any differences observed in random blood glucose measurements (Fig. 4b), insulin levels (Fig. 4c), triacylglycerol levels (Fig. 4d) or adiponectin levels (Fig. 4e). No gross lipid deposits were observed in livers of SST-DTA mice, as measured by Nile Red staining (Fig. 4f,g), though small lipid droplets were observed in mice under both conditions.

\section{SST-DTA mice exhibit increased granulocyte precursors in bone marrow and increased inflammatory state of bone marrow and circulating monocyte pool}

Flow cytometry of lin $^{-}, \mathrm{sca}^{-}, \mathrm{c}^{-\mathrm{kit}}{ }^{+}$cells from SST-DTA and control mice showed an increased percentage (relative to all lin $^{-}, \mathrm{sca}^{-}, \mathrm{c}^{-\mathrm{kit}^{+}}$cells) of GMP cells $\left(\mathrm{CD} 34^{+}\right.$, b

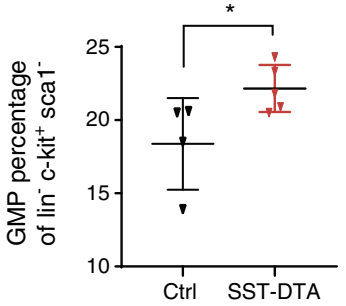

e

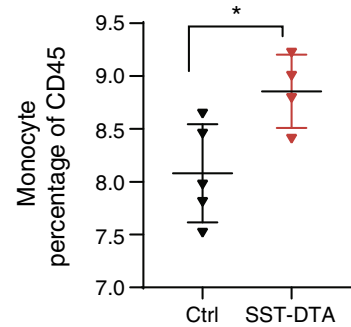

i

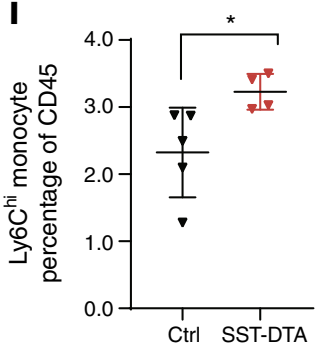

C

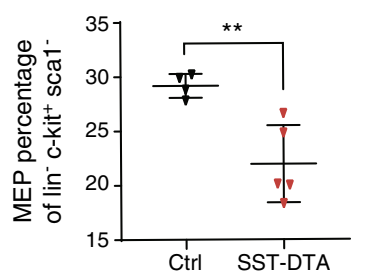

f
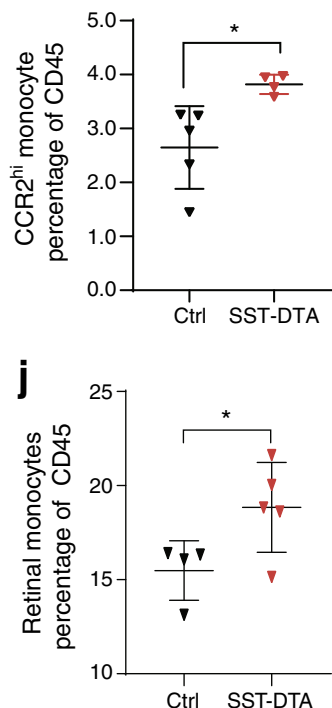

CCR2 ${ }^{\text {hi }}$ monocytes (f). (g-i) Plots of the three circulating monocyte pools, split by Ly6C expression, showing that SST-DT mice exhibited no differences in Ly6 $6 \mathrm{C}^{\mathrm{lo}}$ or Ly6 $\mathrm{C}^{\text {inter }}$ monocytes $(\mathbf{g}, \mathbf{h})$ and an increase in Ly6C ${ }^{\text {hi }}$ monocytes (i). (j) Flow cytometry showed increases in retinal monocytes in DTA-treated mice. $n=4$ or 5 /group. ${ }^{*} p<0.05$ and $* * p<0.01$ for indicated comparison. Ctrl, control; MEP, megakaryocyte-erythroid progenitor

CD16/32 $2^{+}$(Fig. 5a,b). In contrast, a decreased percentage of megakaryocyte-erythroid progenitors was observed in SST-DTA mice (CD34-, CD16/32-) (Fig. 5c). Relative monocyte increases were observed in SST-DTA mice (Fig. 5d,e), as well as increased percentages of proinflammatory $\mathrm{C}-\mathrm{C}$ chemokine receptor type 2 (CCR2)-positive monocytes (Fig. 5f). Examining monocyte subsets by Ly6C expression revealed no changes in Ly6 ${ }^{\text {lo }}$ (Fig. 5g) or Ly $6 \mathrm{C}^{\text {inter }}$ populations (Fig. $5 \mathrm{~h}$ ), although proinflammatory Ly6 $\mathrm{C}^{\text {hi }}$ monocytes were elevated in SST-DTA mice (Fig. 5i). Previously, we reported that two different dysfunctions in the neural axis, hypothalamic inflammation and bone marrow neuropathy, precede retinal microvascular disease and reduced retinal function concomitant with retinal monocytosis $[6,21]$. To assess whether hypothalamic SST neuron depletion recapitulated these findings, retinal flow cytometry was performed at 8 months post-treatment (9 months of age). SST-DTA mice exhibited higher levels of retinal monocytes than control mice (Fig. 5j). 
Fig. 6 SST-DTA mice exhibit changes in retinal function. (a) ERG model diagram showing Awave, B-wave and OP. (b, c) Recordings from SST-DTA mice exhibit deficits in B-wave responses at photopic intensities (b) but not at lower, scotopic light intensities (c) ( $n=8$ control, $n=6$ SST-DTA). (d) A-wave responses are likewise comparable at scotopic light intensities. (e- $\mathbf{- g}) \mathrm{OP}$ onset time is delayed for OP1-3. (h) Optomotor tracking data indicated reduced visual acuity in SST-DTA mice ( $n=4$ /group). ${ }^{*} p<0.05, * * p<0.01$ and $* * * p<0.001$ for indicated comparison. Ctrl, control
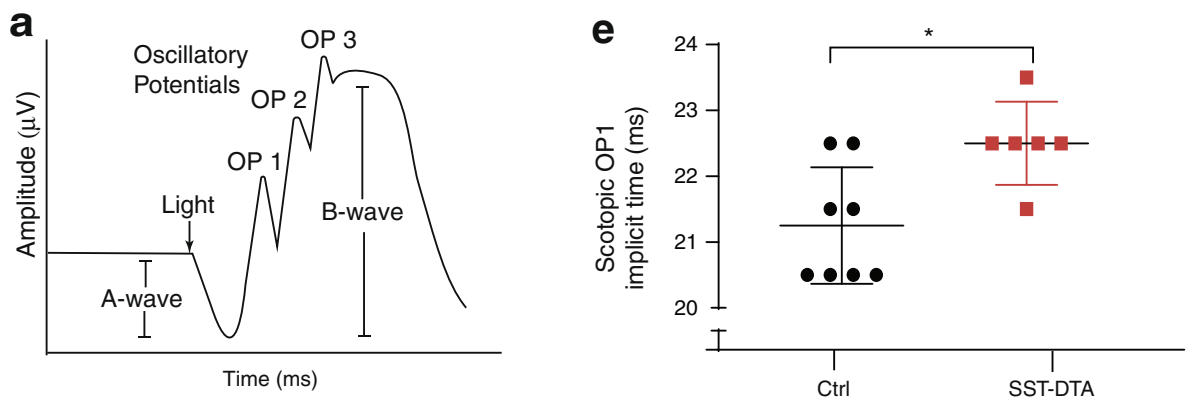

b

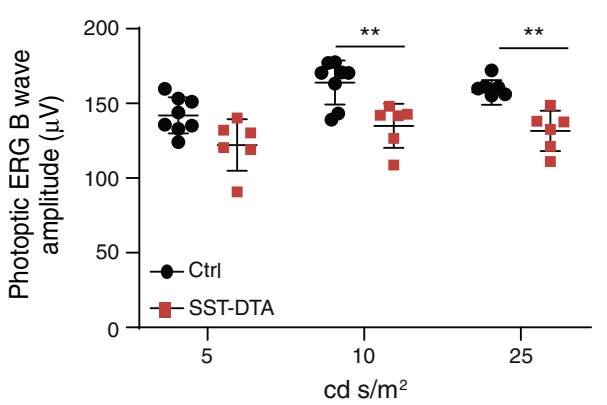

f

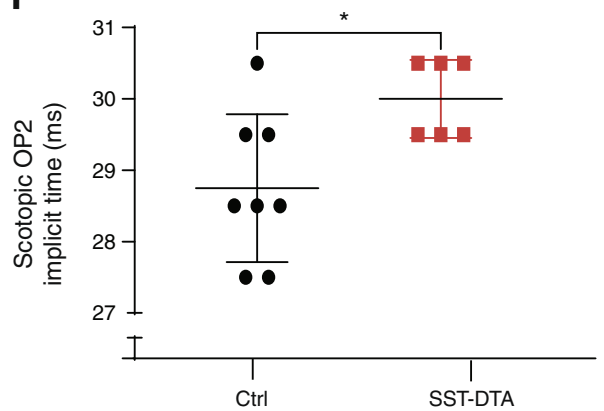

C
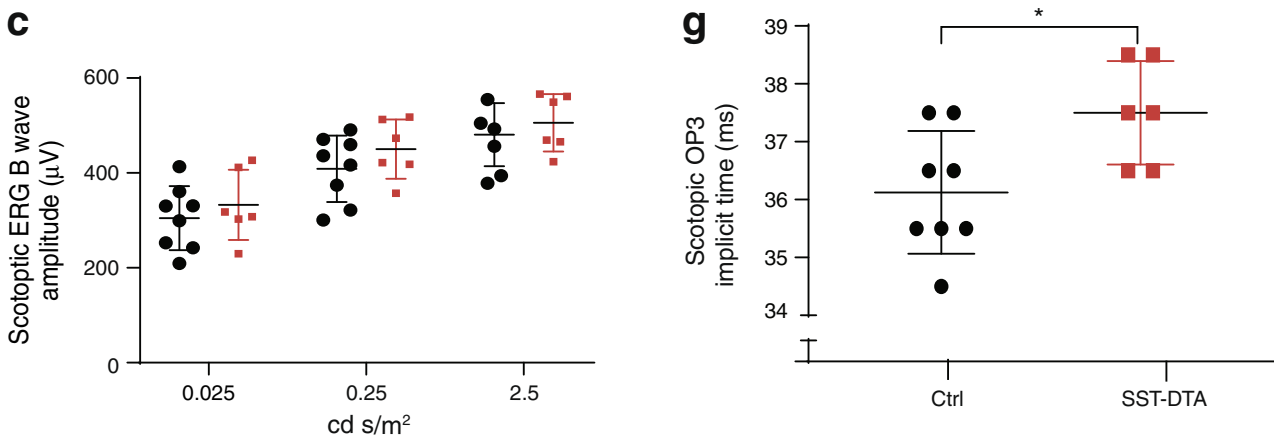

d

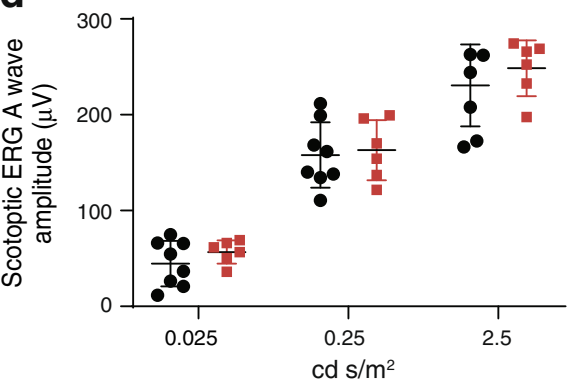

h

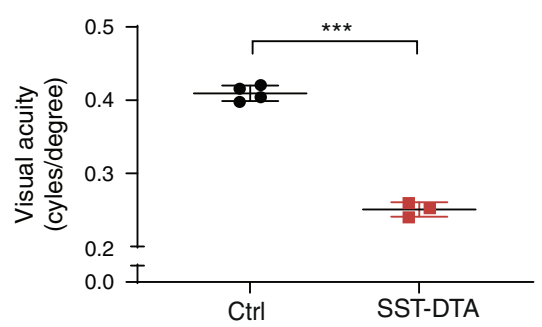

\section{SST-DTA mice exhibit increased retinal monocytes and reduced retinal function}

To assess retinal function in the SST-DTA mouse model, we performed ERG and optomotor tracking. The ERG assays the electrical response of the retina to light (Fig. 6a). The ERG is summed field potential containing a photoreceptor driven Awave and a neural retina (retinal bipolar cell) dominant Bwave. Dim light scotopic ERGs reflect rod photoreceptor activity, whereas photopic ERGs isolate cone photoreceptor activity by delivering a chronic background light to suppress rod photoreceptor activity. Cone photoreceptors are then stimulated by a superimposed bright light stimulus. In addition to A- and B-waves, ERGs exhibit oscillatory potentials (OPs), which have complex, incompletely described origins in the neural retina. Importantly, delayed OP onset occurs early in diabetic retinal dysfunction, prior to frank retinopathy.

SST-DTA mice exhibited disruptions in photopic B-waves (Fig. 6b), but not photopic A-waves or scotopic B-waves (Fig. $6 \mathrm{c}, \mathrm{d})$. Delays in the onset (implicit) time of each OP were 
a

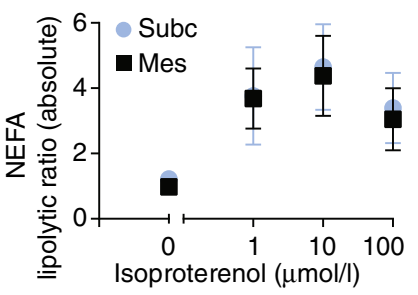

b
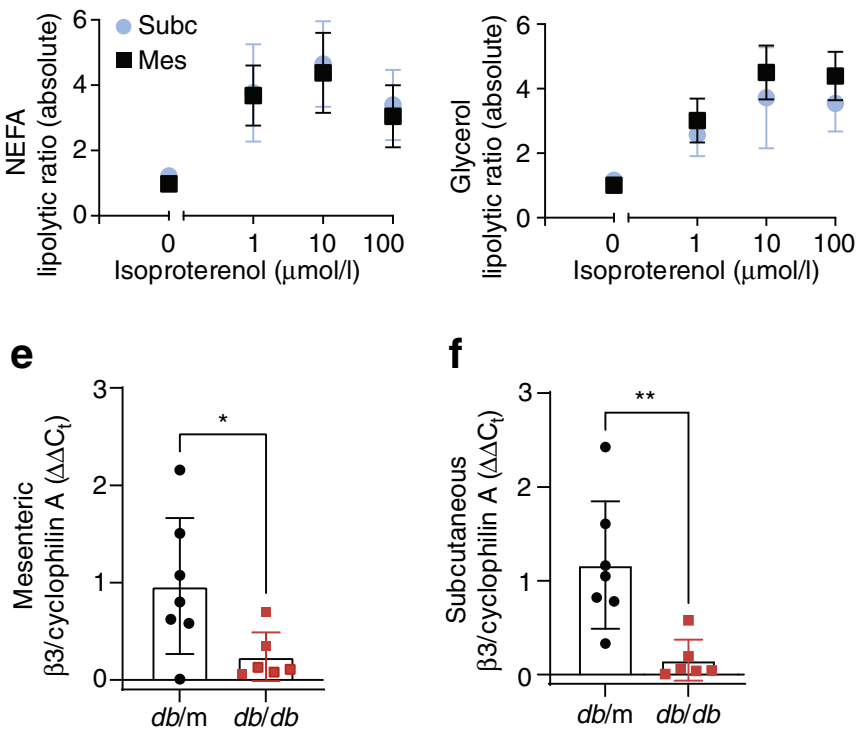

i

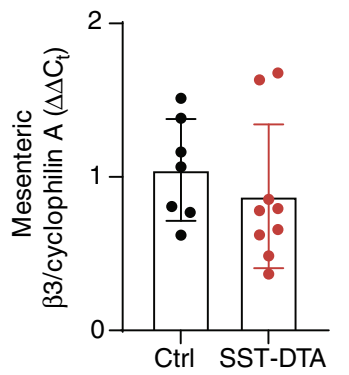

f

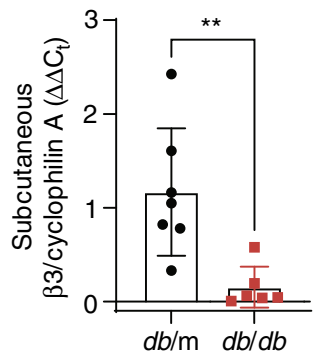

j

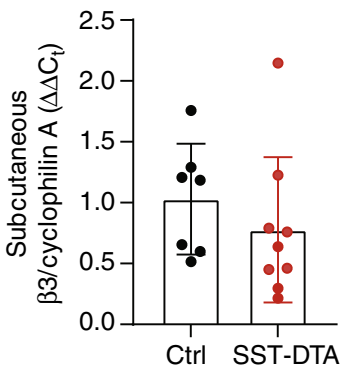

Fig. 7 SST-DTA mice exhibit visceral fat catecholamine resistance. (a, b) Isoprenaline dose-dependently drives the release of NEFA (a) and glycerol (b) from acute subcutaneous and mesenteric fat explants. (c, d) Plots of ex vivo lipolysis in mesenteric (c) and inguinal (d) subcutaneous fat from 12-month-old $d b / d b$ mice show lipolytic catecholamine resistance in both fat pads. (e, f) Quantitative PCR data show $\beta_{3}$-adrenergic receptors are significantly downregulated in mesenteric (e) and subcutaneous (f) fat from $d b / d b$ mice. (g, h) SST-DTA mice exhibit lipolytic catecholamine resistance in mesenteric (g) but not subcutaneous (h)

C

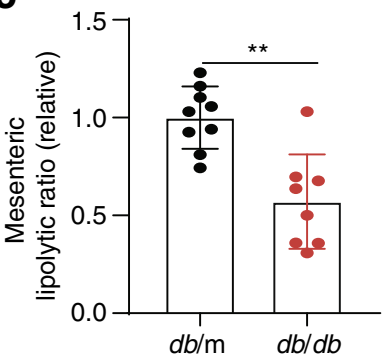

d

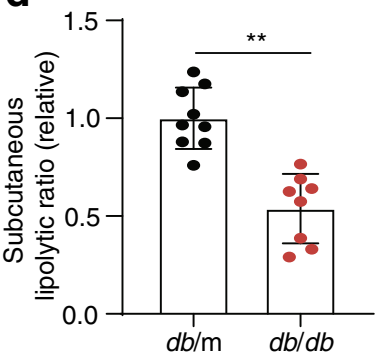

g

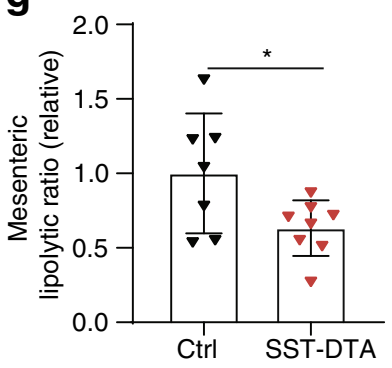

h

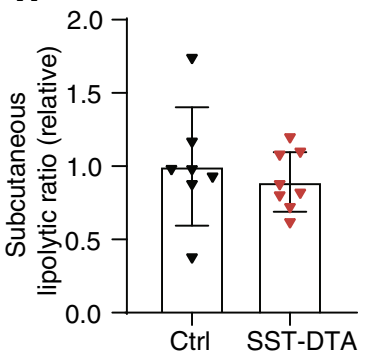

k

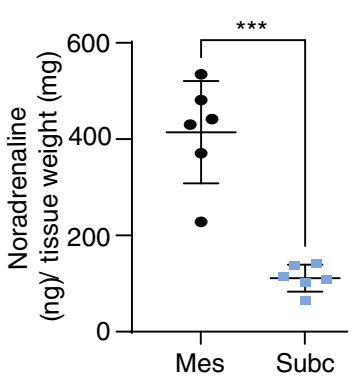

I

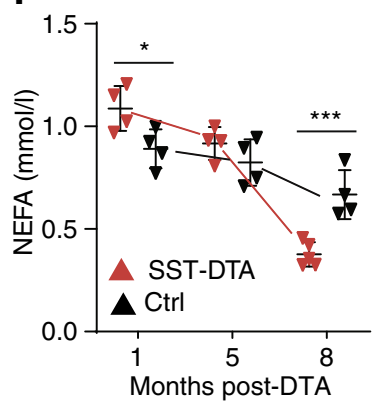

adipose tissue. (i, j) Quantitative PCR data show $\beta_{3}$-adrenergic receptors are not significantly downregulated in mesenteric (i) and subcutaneous (j) fat from SST-DTA mice. (k) Noradrenaline concentration in mesenteric and subcutaneous fat from wild-type mice, measured by HPLC and electrochemical detection, indicates higher basal noradrenaline content in mesenteric fat. (I) Serial plasma NEFA measurements in SST-DTA and control mice show dynamic alterations in fatty acid homeostasis in the SST-DTA model ( $n=7 /$ group). $* p<0.05, * * p<0.01$ and $* * * p<0.001$ for indicated comparison. Ctrl, control; Mes, mesenteric; Subc, subcutaneous

detected in SST-DTA mice (Fig. 6e-g). Finally, in a second measure of retinal function, we examined optomotor tracking, a behavioural measure of visual acuity. SST-DTA mice exhibited profound reductions in spatial acuity (Fig. 6h) from 0.4 cycles/degree in control mice to 0.25 cycles per degree in SST-DTA mice.

\section{SST-DTA mice exhibit adipose catecholamine resistance in mesenteric fat}

An important implication of the above studies is that SST neuronal loss could induce pathology in many tissues. One key tissue to consider in this regard is white adipose tissue. In rodents, visceral, mesenteric fat (mWAT) is richly connected to the hypothalamus, particularly the PVN [34]. Because sympathetic nerves drive lipolysis through catecholamine signalling in adipose tissue, we hypothesised that mWAT might have impaired lipolytic function in SST-DTA mice. To measure catecholamine-induced lipolysis, we established a dose-response curve of mWAT and subcutaneous inguinal fat (iWAT) in response to isoprenaline, a $\beta$ adrenergic receptor agonist, finding that in wild-type mice, both tissues exhibited comparable NEFA and glycerol release (Fig. 7a,b). Using this method, we measured catecholamine sensitivity in $d b / d b$ mice. Compared with their heterozygote littermate controls, 6- to 12-month-old $d b / d b$ mice exhibited catecholamine resistance in both mWAT and iWAT (Fig. $7 \mathrm{c}, \mathrm{d})$, as well as significant $\beta_{3}$-adrenergic receptor 
downregulation in both tissues (Fig. 7e,f). In contrast, iWAT from SST-DTA mice exhibited similar catecholamine sensitivity to iWAT from control mice but catecholamine-induced lipolysis was suppressed by $50 \%$ in SST-DTA mWAT (Fig. $7 \mathrm{~g}, \mathrm{~h})$. However, SST-DTA mice did not exhibit receptor downregulation at the level of mRNA (Fig. 7i,j). Because chronic release of noradrenaline could drive desensitisation to catecholamines, we examined the noradrenaline concentration in iWAT and mWAT, finding significantly higher levels in mWAT than in iWAT in wild-type mice (Fig. 7k). To further examine the sympathetic nerve-adipose circuit, which drives NEFA release, we examined plasma NEFA in SSTDTA mice. At 8 months of age, SST-DTA mice exhibited a $40 \%$ reduction in plasma NEFA (Fig. 71). Examining NEFA content of archived plasma samples from monthly blood draws showed a striking pattern of early elevations in NEFA content at 1 month post-DTA, followed by comparable NEFA levels at 5 months post-DTA, culminating in the aforementioned reduction at 8 months (Fig. 71).

\section{Discussion}

The current study adds to a growing literature indicating that hypothalamic inflammation is an important site of pathology in metabolic disease. For example, mice subjected to high-fat diet (HFD) show hypothalamic inflammation after $24 \mathrm{~h}$, particularly in astrocytes and microglia [3]. After months of HFD, the hypothalamus exhibits apoptotic cell death [35]. Genetic models of the metabolic syndrome recapitulate the sequence of hypothalamic inflammation and cell death [36]. The present data inform our understanding of hypothalamic SST neurons in this process. While somatostatin uniformly suppresses cytokine release in the periphery, information on its anti-inflammatory action in the brain is more conflicting and largely derived from cell culture studies [16, 18, 19]. The data presented here suggest that SST neurons repress CNS inflammation. In addition to their anti-inflammatory function, SST neurons also secrete the classically inhibitory neurotransmitters GABA and glycine in brainstem and cortex [8], though recent data indicate that some hypothalamic SST neurons are glutamatergic [37]. In brief, the molecular heterogeneity of SST neurons requires functional characterisation; our c-Fos activation data suggest that SST neurons exhibit local inhibitory roles in the hypothalamus. The loss of these neurons could have an extensive impact on the many tissues under hypothalamic regulation through the SNS.

Sympathetic nerves regulate haematopoiesis, and in diabetes, dysfunction in this circuit increases short-term repopulating haematopoietic stem cells and suppresses longterm repopulating haematopoietic stem cells, biasing haematopoiesis towards myeloid progenitors and increasing blood monocytes [6, 21, 38-41]. We previously found that models of type 1 and type 2 diabetes show decreased bone marrow tyrosine hydroxylase and CGRP, indicating frank neuropathy [21, 24]. However, loss of hypothalamic SST neurons was theorised to hyperactivate the bone marrow circuit prior to neuropathy [20]. Indeed, SST-DTA mouse bone marrow demonstrated a haematopoietic bias towards GMPs, recapitulating findings recently published in $d b / d b$ mice [42]. Additionally, peripheral blood monocytes were increased and preferentially proinflammatory CCR $2^{\text {hi }}$ and

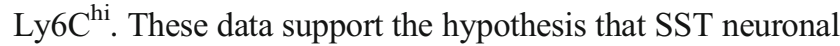
dysfunction plays a role in diabetic bone marrow.

Retinal dysfunction, mediated by vascular injury and immune infiltrate, is a common feature of diabetes. We observe increases in retinal monocytes in SST-DTA mice, and this finding was accompanied by delays in the implicit times of ERG OP, which is the most common ERG dysfunction identified in diabetic individuals [43]. In mouse models, delayed OP implicit time precedes retinal vascular damage in chronically HFD-fed mice, suggesting a step-wise pathophysiology linking inflammation to retinal dysfunction and eventual vascular damage [44]. We confirmed the functional importance of the above pathologies with the finding that SST-DTA mice exhibit reduced spatial acuity.

Sympathetic nerves also regulate white adipose tissue. Dysfunction in this tissue is of vital importance to diabetes and the metabolic syndrome, especially in visceral fat. mWAT, the only true visceral fat pad in rodents [45], is richly represented at the hypothalamic PVN [34]. We observe a well-characterised hallmark of metabolic disease in SSTDTA mouse mWAT: adipose catecholamine resistance. We hypothesise that hyperactivity of adipose sympathetic nerves (and resultant catecholamine excess) drives adipose catecholamine resistance. In support of this view, we assessed local concentrations of noradrenaline in $\mathrm{mWAT}$ and $\mathrm{iWAT}$, finding markedly elevated concentrations in the former. However, our data cannot rule out other potential causes. For example, in vitro incubation of adipocytes with TNF- $\alpha$ reduces lipolysis in response to $\beta$-adrenergic agonists [46], suggesting that inflammation could aggravate catecholamine resistance. Adipose tissue releases NEFA during lipolysis and the only plasma metabolite that differed between SST-DTA mice and controls were NEFA, which showed dynamic differences: an early increase followed by a late decline. Increased NEFA in individuals with type 2 diabetes are driven by increased basal lipolysis; indeed, even non-diabetic individuals with family histories of diabetes exhibit enhanced basal lipolysis [27]. In contrast, we observe a deficit in induced lipolysis. We speculate that in the late stages of our mouse model, reduced plasma NEFA are a plausible correlate of isolated catecholamine resistance. Adipose catecholamine resistance is an early finding in disease progression [30] and predicts type 2 diabetes and worsening insulin resistance [28], although we did not observe signs of insulin resistance in these mice. Placing 
SST-DTA mice on an HFD may lead to greater insights regarding the role of SST neurons in metabolism.

A relative weakness of our study is that brain inflammation was principally assessed by cellular mediators of inflammation: astrocytes and microglia. Prior data indicate that somatostatin negatively regulates prostaglandin- $\mathrm{E}_{2}$ synthesis in microglia and IL-6 secretion in astrocytes. As such, future studies in this model should assess cytokine mediators of inflammation. Microglial polarisation towards an M1 phenotype is often observed in the disease state and evaluation of cell-surface markers such as CD16/32 and CD206 would likewise be fruitful in future studies. An additional limitation is that neuronal function was principally assessed by c-Fos measurements and static noradrenaline content. An important future direction would be to measure nerve activity or noradrenaline turnover. Additionally, while our studies indicate that SST neuronal loss induces several pathologies, future studies may examine the effect of specifically antagonising somatostatin itself (e.g. by RNA interference). Finally, our reporter line exhibits somatostatin knockdown in homozygous mice [47]. Though we only used heterozygote mice, another future direction would be to confirm these results in a different mouse line.

In summary, depleting hypothalamic SST neurons recapitulated many early phenotypes found in diabetes that precede frank neuropathy or vascular insult. The significance of this finding is that this small but significant population of neurons impacts many target tissues of diabetic complications including the brain, bone marrow, retina and visceral adipose tissue. Pathology resulting from the loss of SST neurons can potentially be corrected by pharmacological strategies, including the use of somatostatin analogues such as octreotide, delivered intranasally, to target the hypothalamus.

Supplementary Information The online version of this article (https://doi. org/10.1007/s00125-021-05549-6) contains peer-reviewed but unedited supplementary material.

Data availability The datasets generated and/or analysed during the current study are available from the corresponding author on reasonable request.

Funding This study was supported by grants from the National Institutes of Health (grant R01EY028037 R01EY028037, R01EY012601, R01EY028858 and R01EY025383 to MB) and Medical Scientist Training Program (grant T32 GM008361), and by Research to Prevent Blindness-Unrestricted Grants. The Vanderbilt Hormone Assay Core is supported by NIH grants DK059637 (MMPC) and DK020593 (DRTC).

Authors' relationships and activities The authors declare that there are no relationships or activities that might bias, or be perceived to bias, their work.

Contribution statement $\mathrm{CH}$ managed all experiments and data collection and edited the manuscript. RFR collected metabolic data and wrote the manuscript. RB performed the stereotactic surgery. PH performed the tissue processing and immunohistochemistry. YA-A performed optokinetic and ERG recordings, and CPV and ALFL assisted with flow cytometry and bone marrow function assays. GML, PMF and KLG aided in experimental design. All authors contributed to the acquisition and analysis of the data. All the authors revised the manuscript critically for important intellectual content and approved the final version of the manuscript. MBG conceptualised the experiment, obtained funding, designed experiments, assisted with data interpretation, edited the manuscript and is the guarantor of all data in the manuscript.

\section{References}

1. De Angelis K, Senador DD, Mostarda C, Irigoyen MC, Morris M (2012) Sympathetic overactivity precedes metabolic dysfunction in a fructose model of glucose intolerance in mice. Am J Physiol Regul Integr Comp Physiol 302(8):R950-R957. https://doi.org/ 10.1152/ajpregu.00450.2011

2. Garris DR (1995) Developmental and regional changes in brain norepinephrine levels in diabetic C57BL/KsJ mice: effects of estradiol and progesterone. Brain Res Dev Brain Res 89(2):314-319. https://doi.org/10.1016/0165-3806(95)00121-s

3. Thaler JP, Yi CX, Schur EA et al (2012) Obesity is associated with hypothalamic injury in rodents and humans. J Clin Invest 122(1): 153-162. https://doi.org/10.1172/JCI59660

4. Ding L, Kang Y, Dai HB et al (2019) Adipose afferent reflex is enhanced by TNFalpha in paraventricular nucleus through NADPH oxidase-dependent ROS generation in obesity-related hypertensive rats. J Transl Med 17(1):256. https://doi.org/10.1186/s12967-0192006-0

5. Mi Y, Wu Q, Yuan W, Chen F, Du D (2018) Role of microglia M1/ M2 polarisation in the paraventricular nucleus: New insight into the development of stress-induced hypertension in rats. Auton Neurosci 213:71-80. https://doi.org/10.1016/j.autneu.2018.06.003

6. $\mathrm{Hu}$ P, Thinschmidt JS, Caballero S et al (2015) Loss of survival factors and activation of inflammatory cascades in brain sympathetic centers in type 1 diabetic mice. Am J Physiol Endocrinol Metab 308(8):E688-E698. https://doi.org/10.1152/ajpendo.00504.2014

7. Fenton C, Keating GM, Lyseng-Williamson KA (2006) Moxonidine: a review of its use in essential hypertension. Drugs 66(4):477-496. https://doi.org/10.2165/00003495-20066604000006

8. Thek KR, Ong SJM, Carter DC, Bassi JK, Allen AM, McDougall SJ (2019) Extensive Inhibitory Gating of Viscerosensory Signals by a Sparse Network of Somatostatin Neurons. J Neurosci 39(41): 8038-8050. https://doi.org/10.1523/JNEUROSCI.3036-18.2019

9. Boehm S, Huck S (1996) A somatostatin receptor inhibits noradrenaline release from chick sympathetic neurons through pertussis toxin-sensitive mechanisms: comparison with the action of alpha 2-adrenoceptors. Neuroscience 73(2):595-604. https://doi. org/10.1016/0306-4522(96)00074-7

10. Shapiro MS, Hille B (1993) Substance P and somatostatin inhibit calcium channels in rat sympathetic neurons via different $G$ protein pathways. Neuron 10(1):11-20. https://doi.org/10.1016/08966273(93)90237-1

11. Stengel A, Rivier J, Tache Y (2013) Central actions of somatostatin-28 and oligosomatostatin agonists to prevent components of the endocrine, autonomic and visceral responses to stress through interaction with different somatostatin receptor subtypes. Curr Pharm Des 19(1):98-105. https://doi.org/10.2174/ 13816128130114

12. Bowman BR, Bokiniec P, McMullan S, Goodchild AK, Burke PGR (2019) Somatostatin 2 Receptors in the Spinal Cord Tonically Restrain Thermogenic, Cardiac and Other Sympathetic Outflows. Front Neurosci 13:121. https://doi.org/10.3389/fnins. 2019.00121 
13. Karalis K, Mastorakos G, Chrousos GP, Tolis G (1994) Somatostatin analogues suppress the inflammatory reaction in vivo. J Clin Invest 93(5):2000-2006. https://doi.org/10.1172/ JCI117193

14. Peluso G, Petillo O, Melone MA, Mazzarella G, Ranieri M, Tajana GF (1996) Modulation of cytokine production in activated human monocytes by somatostatin. Neuropeptides 30(5):443-451. https:// doi.org/10.1016/s0143-4179(96)90008-6

15. Basivireddy J, Somvanshi RK, Romero IA et al (2013) Somatostatin preserved blood brain barrier against cytokine induced alterations: possible role in multiple sclerosis. Biochem Pharmacol 86(4):497-507. https://doi.org/10.1016/j.bcp.2013.06. 001

16. Dror N, Tveria L, Meniv I, Ben-Shmuel S, Filipovich T, FleisherBerkovich S (2008) Inhibitory effect of somatostatin on prostaglandin E2 synthesis by primary neonatal rat glial cells. Regul Pept 150(1-3):21-25. https://doi.org/10.1016/j.regpep.2008.06.005

17. Grimaldi M, Florio T, Schettini G (1997) Somatostatin inhibits interleukin 6 release from rat cortical type I astrocytes via the inhibition of adenylyl cyclase. Biochem Biophys Res Commun 235(1): 242-248. https://doi.org/10.1006/bbrc.1997.6513

18. Dello Russo C, Lisi L, Navarra P, Tringali G (2009) Diverging effects of cortistatin and somatostatin on the production and release of prostanoids from rat cortical microglia and astrocytes. $\mathrm{J}$ Neuroimmunol 213(1-2):78-83. https://doi.org/10.1016/j. jneuroim.2009.05.016

19. Grinshpun J, Tveria L, Fleisher-Berkovich S (2008) Differential regulation of prostaglandin synthesis in neonatal rat microglia and astrocytes by somatostatin. Eur J Pharmacol 584(2-3):312-317. https://doi.org/10.1016/j.ejphar.2008.02.025

20. Bhatwadekar AD, Duan Y, Korah M et al (2017) Hematopoietic stem/progenitor involvement in retinal microvascular repair during diabetes: Implications for bone marrow rejuvenation. Vis Res 139: 211-220. https://doi.org/10.1016/j.visres.2017.06.016

21. Hu P, Thinschmidt JS, Yan Y et al (2013) CNS inflammation and bone marrow neuropathy in type 1 diabetes. Am J Pathol 183(5): 1608-1620. https://doi.org/10.1016/j.ajpath.2013.07.009

22. Vasamsetti SB, Florentin J, Coppin E et al (2018) Sympathetic Neuronal Activation Triggers Myeloid Progenitor Proliferation and Differentiation. Immunity 49(1):93-106 e107. https://doi.org/ 10.1016/j.immuni.2018.05.004

23. Elsaafien K, Korim WS, Setiadi A, May CN, Yao ST (2019) Chemoattraction and Recruitment of Activated Immune Cells, Central Autonomic Control, and Blood Pressure Regulation. Front Physiol 10:984. https://doi.org/10.3389/fphys.2019.00984

24. Busik JV, Tikhonenko M, Bhatwadekar A et al (2009) Diabetic retinopathy is associated with bone marrow neuropathy and a depressed peripheral clock. J Exp Med 206(13):2897-2906. https://doi.org/10.1084/jem.20090889

25. Young JB, Weiss J, Boufath N (2004) Effects of dietary monosaccharides on sympathetic nervous system activity in adipose tissues of male rats. Diabetes 53(5):1271-1278. https://doi.org/10.2337/ diabetes.53.5.1271

26. Chaves VE, Frasson D, Martins-Santos ME et al (2006) Glyceroneogenesis is reduced and glucose uptake is increased in adipose tissue from cafeteria diet-fed rats independently of tissue sympathetic innervation. J Nutr 136(10):2475-2480. https://doi. org/10.1093/jn/136.10.2475

27. Dahlman I, Ryden M, Arner P (2018) Family history of diabetes is associated with enhanced adipose lipolysis: Evidence for the implication of epigenetic factors. Diabetes Metab 44(2):155-159. https:// doi.org/10.1016/j.diabet.2017.10.010

28. Arner P, Andersson DP, Backdahl J, Dahlman I, Ryden M (2018) Weight Gain and Impaired Glucose Metabolism in Women Are Predicted by Inefficient Subcutaneous Fat Cell Lipolysis. Cell
Metab 28(1):45-54 e43. https://doi.org/10.1016/j.cmet.2018.05. 004

29. Ryden M, Arner P (2017) Subcutaneous Adipocyte Lipolysis Contributes to Circulating Lipid Levels. Arterioscler Thromb Vasc Biol 37(9):1782-1787. https://doi.org/10.1161/ATVBAHA. 117.309759

30. Reynisdottir S, Wahrenberg H, Carlstrom K, Rossner S, Arner P (1994) Catecholamine resistance in fat cells of women with upperbody obesity due to decreased expression of beta 2-adrenoceptors. Diabetologia 37(4):428-435. https://doi.org/10.1007/bf00408482

31. Anaclet C, De Luca R, Venner A et al (2018) Genetic Activation, Inactivation, and Deletion Reveal a Limited And Nuanced Role for Somatostatin-Containing Basal Forebrain Neurons in Behavioral State Control. J Neurosci 38(22):5168-5181. https://doi.org/10. 1523/JNEUROSCI.2955-17.2018

32. Todd WD, Venner A, Anaclet C et al (2020) Suprachiasmatic VIP neurons are required for normal circadian rhythmicity and comprised of molecularly distinct subpopulations. Nat Commun 11(1):4410. https://doi.org/10.1038/s41467-020-17197-2

33. Chung L (2015) A Brief Introduction to the Transduction of Neural Activity into Fos Signal. Dev Reprod 19(2):61-67. https://doi.org/ 10.12717/DR.2015.19.2.061

34. Nguyen NL, Randall J, Banfield BW, Bartness TJ (2014) Central sympathetic innervations to visceral and subcutaneous white adipose tissue. Am J Physiol Regul Integr Comp Physiol 306(6): R375-R386. https://doi.org/10.1152/ajpregu.00552.2013

35. Moraes JC, Coope A, Morari J et al (2009) High-fat diet induces apoptosis of hypothalamic neurons. PLoS One 4(4):e5045. https:// doi.org/10.1371/journal.pone.0005045

36. Garris DR, West RL, Coleman DL (1985) Morphometric analysis of medial basal hypothalamic neuronal degeneration in diabetes $(\mathrm{db} / \mathrm{db})$ mutant C57BL/KsJ mice: relation to age and hyperglycemia. Brain Res 352(2):161-168. https://doi.org/10.1016/01653806(85)90101-4

37. Mickelsen LE, Bolisetty M, Chimileski BR et al (2019) Single-cell transcriptomic analysis of the lateral hypothalamic area reveals molecularly distinct populations of inhibitory and excitatory neurons. Nat Neurosci 22(4):642-656. https://doi.org/10.1038/ s41593-019-0349-8

38. Duan Y, Beli E, Li Calzi S et al (2018) Loss of AngiotensinConverting Enzyme 2 Exacerbates Diabetic Retinopathy by Promoting Bone Marrow Dysfunction. Stem Cells 36(9):1430 1440. https://doi.org/10.1002/stem.2848

39. Nagareddy PR, Murphy AJ, Stirzaker RA et al (2013) Hyperglycemia promotes myelopoiesis and impairs the resolution of atherosclerosis. Cell Metab 17(5):695-708. https://doi.org/10. 1016/j.cmet.2013.04.001

40. Beli E, Dominguez JM 2nd, Hu P et al (2016) CX3CR1 deficiency accelerates the development of retinopathy in a rodent model of type 1 diabetes. J Mol Med (Berl) 94(11):1255-1265. https://doi. org/10.1007/s00109-016-1433-0

41. Barman PK, Urao N, Koh TJ (2019) Diabetes induces myeloid bias in bone marrow progenitors associated with enhanced wound macrophage accumulation and impaired healing. J Pathol 249(4): 435-446. https://doi.org/10.1002/path.5330

42. Vieira CP, Fortmann SD, Hossain M et al (2020) Selective LXR agonist DMHCA corrects retinal and bone marrow dysfunction in type 2 diabetes. JCI Insight 5(13):e137230. https://doi.org/10.1172/ jci.insight. 137230

43. Luu CD, Szental JA, Lee SY, Lavanya R, Wong TY (2010) Correlation between retinal oscillatory potentials and retinal vascular caliber in type 2 diabetes. Invest Ophthalmol Vis Sci 51(1):482486. https://doi.org/10.1167/iovs.09-4069

44. Rajagopal R, Bligard GW, Zhang S, Yin L, Lukasiewicz P, Semenkovich CF (2016) Functional Deficits Precede Structural Lesions in Mice With High-Fat Diet-Induced Diabetic 
Retinopathy. Diabetes 65(4):1072-1084. https://doi.org/10.2337/ db15-1255

45. Rytka JM, Wueest S, Schoenle EJ, Konrad D (2011) The portal theory supported by venous drainage-selective fat transplantation. Diabetes 60(1):56-63. https://doi.org/10.2337/db10-0697

46. Li M, Wang M, Liu Y et al (2019) TNF-alpha Upregulates IKKepsilon Expression via the Lin28B/let-7a Pathway to Induce Catecholamine Resistance in Adipocytes. Obesity (Silver Spring) 27(5):767-776. https://doi.org/10.1002/oby.22434
47. Viollet C, Simon A, Tolle V et al (2017) Somatostatin-IRES-Cre Mice: Between Knockout and Wild-Type? Front Endocrinol (Lausanne) 8:131. https://doi.org/10.3389/fendo.2017.00131

Publisher's note Springer Nature remains neutral with regard to jurisdictional claims in published maps and institutional affiliations. 